Case Report

\title{
A Simple Technique Using a Modified Nance Appliance as Anchorage for Maxillary Molar Distalization-Two Case Reports
}

\author{
Chenshuang Li (D) and Chun-Hsi Chung *
}

Citation: Li, C.; Chung, C.-H. A Simple Technique Using a Modified Nance Appliance as Anchorage for Maxillary Molar Distalization-Two Case Reports. Appl. Sci. 2022, 12, 768. https://doi.org/10.3390/ app12020768

Academic Editor: Mitsuru Motoyoshi

Received: 20 November 2021

Accepted: 11 January 2022

Published: 13 January 2022

Publisher's Note: MDPI stays neutral with regard to jurisdictional claims in published maps and institutional affiliations.

Copyright: (C) 2022 by the authors. Licensee MDPI, Basel, Switzerland. This article is an open access article distributed under the terms and conditions of the Creative Commons Attribution (CC BY) license (https:/ / creativecommons.org/licenses/by/ $4.0 /)$.
Department of Orthodontics, School of Dental Medicine, University of Pennsylvania, 240 South 40th Street, Philadelphia, PA 19104, USA; lichens@upenn.edu

* Correspondence: chunc@upenn.edu; Tel.: +1-215-898-7130

Featured Application: The current technique could be applied to patients who need maxillary molar distalization. It uses a modified Nance appliance as anchorage and intra-arch mechanics without any Class II elastics.

\begin{abstract}
Maxillary molar distalization to correct a dental Class II molar relationship and to create space to relieve crowding has been a long-lasting subject of debate in orthodontics. Generally, to distalize maxillary molars, an intra-arch distalization appliance is favored over an inter-arch appliance since it does not utilize mandibular dentition as an anchorage, so some unwanted side effects on mandibular incisors can be avoided. A variety of intra-arch appliances have been developed to distalize maxillary molars, such as the pendulum, Jones jig, first class appliance, distal jet, and modified C-palatal plate. Although they could achieve efficient molar distalization, the learning curve of proper appliance insertion and activation is relatively long. In addition, the appliances are not comfortable for the patients due to the bulky activation units, especially when the activation units are designed in the palatal area. The current manuscript describes a novel and effective maxillary intra-arch molar distalization appliance-a modified Nance appliance technique, which consists of: (1) palatally, a big acrylic button against the palatal rugae and connected to the premolars with wide mesh pads; (2) buccally, regular brackets on maxillary premolars and first molars with sectional round stainless steel archwires and open coil springs between the second premolar and first molar. Either bilateral or unilateral maxillary molar distalization can be achieved with this appliance, and the Class II elastics are not needed. It is simple to be fabricated, delivered, and activated, and it is comfortable for patients.
\end{abstract}

Keywords: orthodontics; molar distalization; modified Nance appliance; intra-arch mechanics

\section{Introduction}

Tooth size arch-length discrepancy is common in orthodontic treatment [1]. For minimal to moderate amounts of crowding or incisor proclination in the maxilla of a Class II malocclusion, the distalization of molars is often used to avoid extraction [2]. In addition, for a patient with an acceptable profile and skeletal pattern and mild Class II molar malocclusion, intra-arch molar distalization without involving mandibular dentition (such as Class II elastics) is preferred, so the mandibular anterior teeth will not be mesialized and proclined [3]. Nevertheless, molar distalization is the only way to achieve orthodontic treatment goals in certain conditions, such as a patient with previous upper premolar extraction who still presents an excessive overjet, or a skeletal Class III patient with previous upper premolar extraction but who needs further upper anterior teeth retraction to create reverse overjet as pre-surgical orthodontic decompensation [4]. Thus, how to distalize the maxillary molars efficiently has long been a subject of debate in the orthodontic field. 
Based on the location of the anchorage, the maxillary molar distalization strategies can be classified into (1) inter-arch mechanics, which engages the mandibular dentition as the anchorage unit [5], and (2) intra-arch mechanics, which utilizes the support from the cranium, the maxillary bony structure, or the rest of the maxillary dentition [3]. The commonly used inter-arch strategies include Class II elastics [6], Carrier 3D Motion appliance [7], Forsus fatigue resistant device [8], mandibular anterior repositioning appliance (MARA) [9], Herbst appliance [10], and SAIF-springs [11]. The treatment efficiency of Class II elastics and Carrier 3D Motion appliance largely relies on patients' compliance. In addition, for some of the appliances mentioned above, there are also data concerning their acceptance by patients [12]. In a survey conducted previously, a great number of patients reported difficulty in eating soon after the positioning of the fixed device, which improved with time [13]. In addition, sleep and personal appearance were sometimes negative with the considered fixed devices [12]. Other side effects were also reported, such as toothache, wide opening difficulties, aching jaws, difficulty in keeping the appliance clean, and soreness on the lip/cheek from rubbing [12]. Most importantly, all the inter-arch strategies may cause mandibular dentition mesialization and mandibular incisor proclination, which is unfavorable for patients who already presented with proclined mandibular anterior teeth and thin phenotype gingival tissue. An excessive mandibular incisor proclination would cause alveolar bone loss and gingival recession [14].

To avoid unfavorable proclination and periodontal complications with the mandibular anterior dentition, intra-arch maxillary molar distalization strategies should be considered. Headgear is a conventional appliance for maxillary molar distalization using extra-oral anchorage. However, the headgear's efficiency depends on the patient's compliance [15]. To address this issue, a variety of intra-arch strategies have been developed in the past two decades, such as the pendulum [16], Jones jig [17], first class appliance [18], distal jet [19], modified C-palatal plate with the support of mid-palatal temporary anchorage devices (TADs) [20], as well as power chain or nickel-titanium (NiTi) coil connected with buccal alveolar TADs [21]. Although all these appliances could achieve maxillary molar distalization, there are some concerns in their clinical usage. Firstly, the activation unit of the majority of these devices is palatally positioned and relatively bulky, which could lead to patient discomfort. Previous studies showed that, compared to patients with buccal orthodontic appliances, patients with lingual appliances experience discomfort for a longer time [22-24]. Patients with lingual appliances also reported higher speech difficulties, soft tissue irritations, and chewing difficulty than those with buccal appliances [25]. In addition, due to the poor accessibility, the lingual technique is more challenging in terms of treatment approach and needs longer chairside time when compared with the labial technique [26]. Thus, when the activation/reactivation procedures need to be performed intraorally at the palatal area, it necessitates a lot of expertise and time from the orthodontists and good cooperation from the patients. For a patient with a smaller mouth open range or one who cannot hold their mouth wide open, activating the palatal appliance intraorally becomes a very difficult task. Secondly, for some designs of palatal appliances, the amount of activation that each appliance can achieve is limited by how the appliances were fabricated. For instance, the Jones jig, first class appliance, and distal jet function by having the molar tubes slide on the palatal/buccal arm. Thus, the length of the palatal/buccal arm extended distally is the limitation of the total activation of the appliance. If the arm is not long enough to achieve the treatment objectives, a second appliance is needed, which not only increases the lab cost but also prolongs the treatment time. Thirdly, certain palatal devices do not allow unilateral distalization. For example, a modified C-palatal plate has a modified transpalatal arch (TPA) connecting left and right molars rigidly. While connecting the TPA with the palatal temporary anchorage devices (TAD) supported plate by power chains or NiTi springs, a similar amount of distalization force will be applied to the molars on both sides [27]. Thus, in the scenario that only unilateral distalization is needed, or different amounts of distalization are planned for left and right sides, such appliances do not meet clinical needs. Fourthly, although buccal alveolar TADs supported mechanics could be 
utilized to achieve both bilateral and unilateral molar distalization, the local anatomic structure (such as maxillary sinus floor, adjacent tooth roots) [28-30] and bone quality [31] sometimes limit the usage of maxillary buccal alveolar TADs. Last but not least, the high complexity of the palatal appliances requires better hand skills of the lab technicians and longer fabrication time. To improve the chairside treatment efficiency and increase the patients' comfort level during the treatment, new intra-arch molar distalizers are needed.

The current manuscript intends to introduce a novel and effective maxillary molar distalization appliance- - a modified Nance appliance technique that is simple to be fabricated, delivered, and activated. In addition, it is comfortable for the patients.

\section{Appliance Design and Activation}

The technique of using a modified Nance appliance as the anchorage is composed of palatal and buccal parts.

Palatally, a large acrylic button against the palatal rugae is needed. It should be large enough to cover almost the entire rugae. The margin of the acrylic button should be smooth and rounded and be located $2-3 \mathrm{~mm}$ away from the gingival margin of the anterior teeth, which aims to avoid gingival irritation. Laterally, the acrylic button connects to the premolars with stainless steel mesh pads. It can be one or two premolars on each side. The left and right mesh pads are connected by soldering to 0.40 -inch stainless steel wires, which are embedded in the acrylic button. The mesh pads should be in a half-moon shape and cover most of the lingual surface of the premolars to increase the bonding strength. The cementation of this modified Nance appliance follows the standard bracket bonding protocol, including premolar palatal surface cleaning, acid etching, primer application, and applying composite resin on the mesh pads. No special bonding reagent is needed.

Buccally, on the side that needs molar distalization (unilateral or bilateral based on treatment objectives), 0.022-inch slot brackets are bonded to maxillary premolars, and 0.022inch slot molar bands are cemented to the first molars. The brackets' positions are adjusted to allow for the direct insertion of a 0.018-inch stainless steel (SS) archwire passively and smoothly right after bonding. When delivered, both ends of the segmental SS archwire should be cinched to secure the archwire in place. The length of the archwire should be 2-3 $\mathrm{mm}$ longer than the distance between the distal of the first molar tube and the mesial of the premolar bracket so that the molar tube can slide along the archwire during molar distalization. The distalization force is applied by utilizing open coil springs compressed between the molar tube and second premolar bracket. Both NiTi and SS open coil springs can be used.

The patients should be checked monthly. Sometimes the archwire should be replaced, allowing enough free wire for the molar distalization. The open coil springs should also be changed to secure consistently distalizing force. During the molar distalization, a gable bend between the second premolars and first molars can be added to the archwire to help correct molar root angulation. Sometimes headgear can also be added to facilitate the distalization of the molar roots. Based on the authors' clinical observation, the distalization rate is about $0.5 \mathrm{~mm}$ per month. Before discontinuing the open coil, overcorrection to the super Class I molar relationship should be achieved to compensate for some anchorage loss during later anterior teeth and premolar retraction.

Once the overcorrection of the molar distalization has been accomplished, the modified Nance appliance can be removed. Then, a new Nance appliance with a big acrylic button connecting to the molar bands is delivered to hold the molars in place. The premolar brackets should be repositioned to the ideal positions. In addition, the canine should be bonded if sectional mechanics are planned, or the whole maxillary arch should be bonded if the continuous arch technique is preferred. Then the leveling and aligning and distalization of the canine and premolars to the created space could be started, and the incisors can be retracted if needed. 


\section{Clinical Case Demonstrations}

\subsection{Bilateral Ditalization Case-Single Arch Treatment}

An adolescent patient presented with a mild Class II dental relationship and crowding on the maxillary arch. The patient had no significant past medical or past dental history. Intraoral examination showed the patient was in permanent dentition with all the second molars fully erupted (Figure 1). Anterior-posteriorly, there were bilateral end-on Class II canine and molar relationships, with the overjet within the normal limit. Both the maxillary and mandibular incisors were in their normal position. The maxillary dental midline was $1 \mathrm{~mm}$ to the left in relation to the facial midline, and the mandibular dental midline was coincident with the facial midline. There was no posterior crossbite, and the curve of Wilson was within the normal limit. The overbite and the curve of Spee were within the normal limit. There was a mild arch length discrepancy in the maxillary arch, while the mandibular arch was relatively well aligned. No significant Bolton discrepancy was detected. Scalloped alveolar bone morphology was noticed in the mandibular anterior region, indicating the thin alveolar bone support in the labial side of the mandibular anterior teeth.
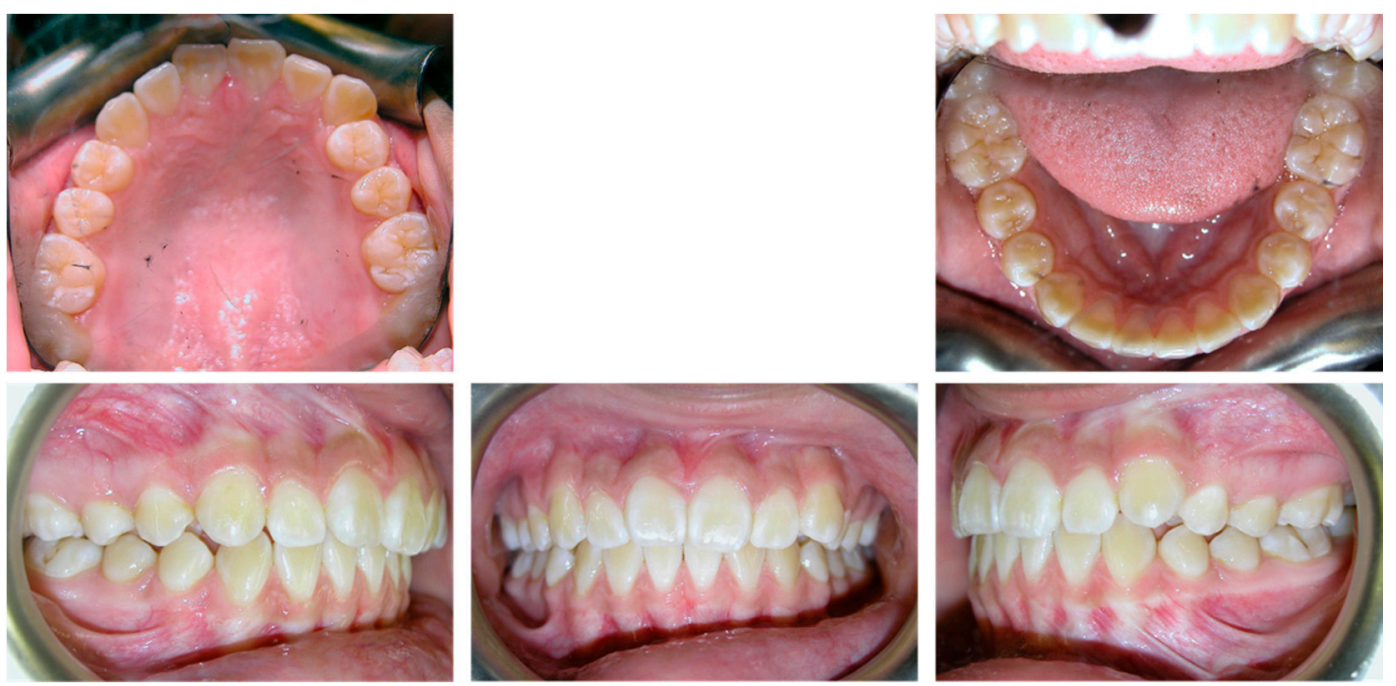

Figure 1. The initial intraoral photos of case 1. Scalloped alveolar bone morphology was noticed in the mandibular anterior region.

Due to the well-aligned mandibular arch and the prominent roots of mandibular incisors, it was decided not to use any inter-arch mechanics. So only the maxillary arch was treated. The treatment objectives were to (1) distalize the maxillary posterior quadrants to achieve canine and molar Class I relationships and to relieve crowding on both sides; (2) maintain the maxillary anterior teeth anterior-posteriorly and vertically, while correcting the maxillary dental midline; and (3) keep the mandibular arch untreated.

Based on the treatment objectives, the treatment plan was designed as follows: (1) distalize the maxillary molar on both sides to super Class I with the modified Nance appliance technique, then distalize the maxillary premolars and canines to achieve Class I canine and molar relationships on both sides; (2) utilize the spaces created by maxillary posterior teeth distalization to correct maxillary anterior crowding and dental midline deviation; (3) no treatment on the mandibular arch. The treatment plan was well-accepted by the patient and parents.

The modified Nance appliance with a big acrylic button as the anchorage was delivered with mesh pads cemented to four maxillary premolars (Figure 2, left). Next, maxillary premolar brackets were bonded, and the segmental 0.018 SS-inch archwires with open coil springs were delivered as described above. The open coil springs were kept active until a super Class I molar relationship was achieved bilaterally (Figure 2, middle; Figure 3). Then, the appliance was removed, and a new Nance appliance with a big acrylic button 
connecting to the maxillary first molar bands was fabricated and cemented (Figure 2, right). Next, the rest of the maxillary arch was bonded, and leveled and aligned starting with continuous NiTi archwire and then 0.018-inch SS archwire. At the same time, the maxillary left premolars and canine were distalized by power chaining canine and premolars to the first molar (Figure 2, right).
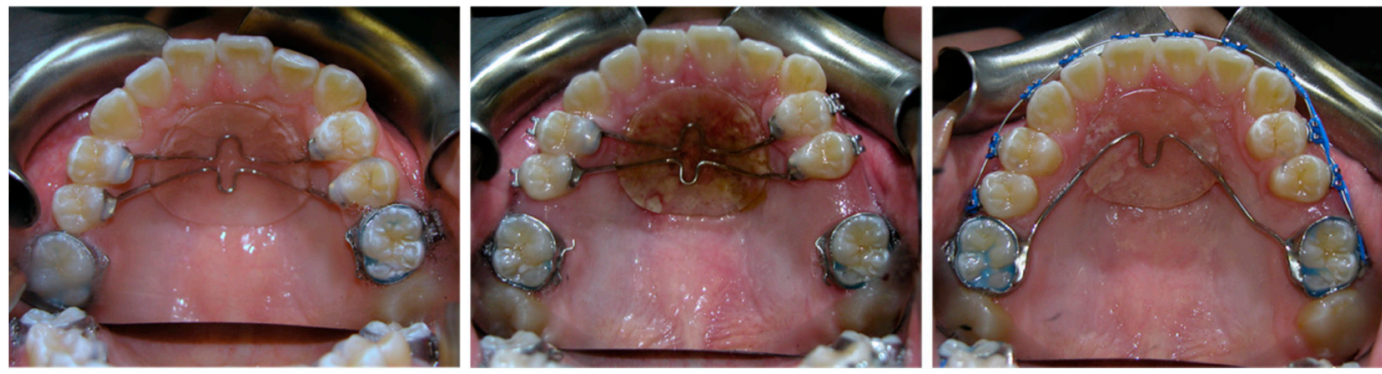

Figure 2. The intraoral progress photos of case 1 demonstrate the treatment sequence of the maxillary arch with the modified Nance appliance technique. From left to right, the maxillary arch photos represent: the delivery of modified Nance appliance (left); the end of molar distalization with modified Nance appliance (middle); the initiation of maxillary arch leveling and aligning with NiTi archwire, and left premolar distalization with power chain after delivering a new Nance appliance and repositioning the brackets (right). In the middle photo, the termination of molar distalization was determined by achieving a super Class I molar relationship on both sides, as demonstrated in Figure 3.
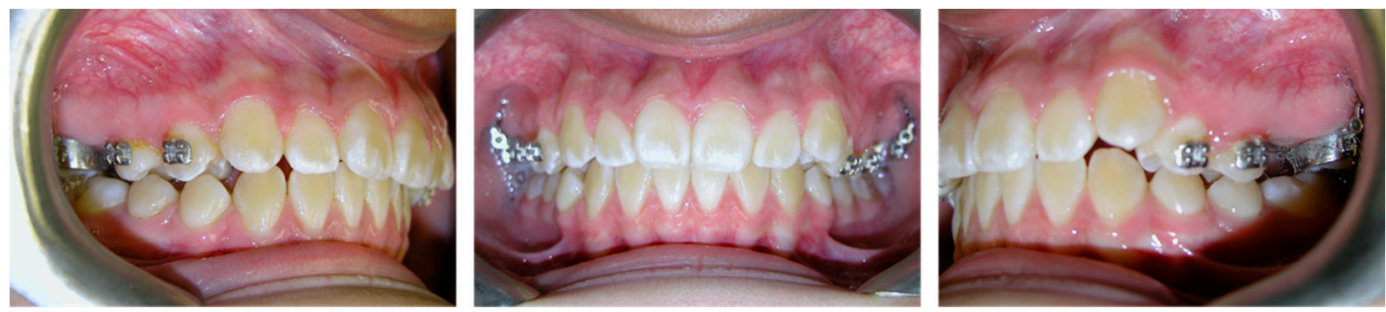

Figure 3. The intraoral progress photos of case 1 demonstrate the bilateral super class I molar relationship achieved with the modified Nance appliance technique. The photos of the right buccal, front, and left buccal views were taken at the same time as the middle photo in Figure 2.

After premolars and canines were distalized, enough spaces had been created to correct maxillary anterior crowding and maxillary dental midline deviation. The treatment of the maxillary arch was finished on a rectangular SS archwire (Figure 4). At the end of the treatment, bilateral Class I canine and molar relationships were achieved, with a well-aligned maxillary arch, ideal overbite and overjet, as well as functional and esthetic occlusion (Figure 5).

\subsection{Unilateral Ditalization Case}

An adolescent patient presented with significant maxillary and mild mandibular anterior crowding, maxillary right lateral incisor in crossbite, and end-on Class II on the right first molar and canine. The patient had no significant past medical or past dental history. Intraoral examination showed the patient was in permanent dentition with all the second molars partially erupted (Figure 6). Anterior-posteriorly, the patient presented Class I canine and molar relationships on the left side, and Class II canine and molar relationships on the right side. The maxillary left lateral incisor was edge-to-edge with the mandibular left lateral incisor and canine, and the maxillary right lateral incisor was in crossbite. The maxillary incisors were slightly retroclined and normotrusive, while the mandibular incisors were normoclined and normotrusive. The maxillary dental midline was $1 \mathrm{~mm}$ to 
the right of the facial midline, and the mandibular dental midline was coincident with the facial midline. There was no posterior crossbite, and the curve of Wilson was within the normal limit. Both the overbite and the curve of Spee were within the normal limit. There was mild crowding in the mandibular arch. No significant Bolton discrepancy was detected.
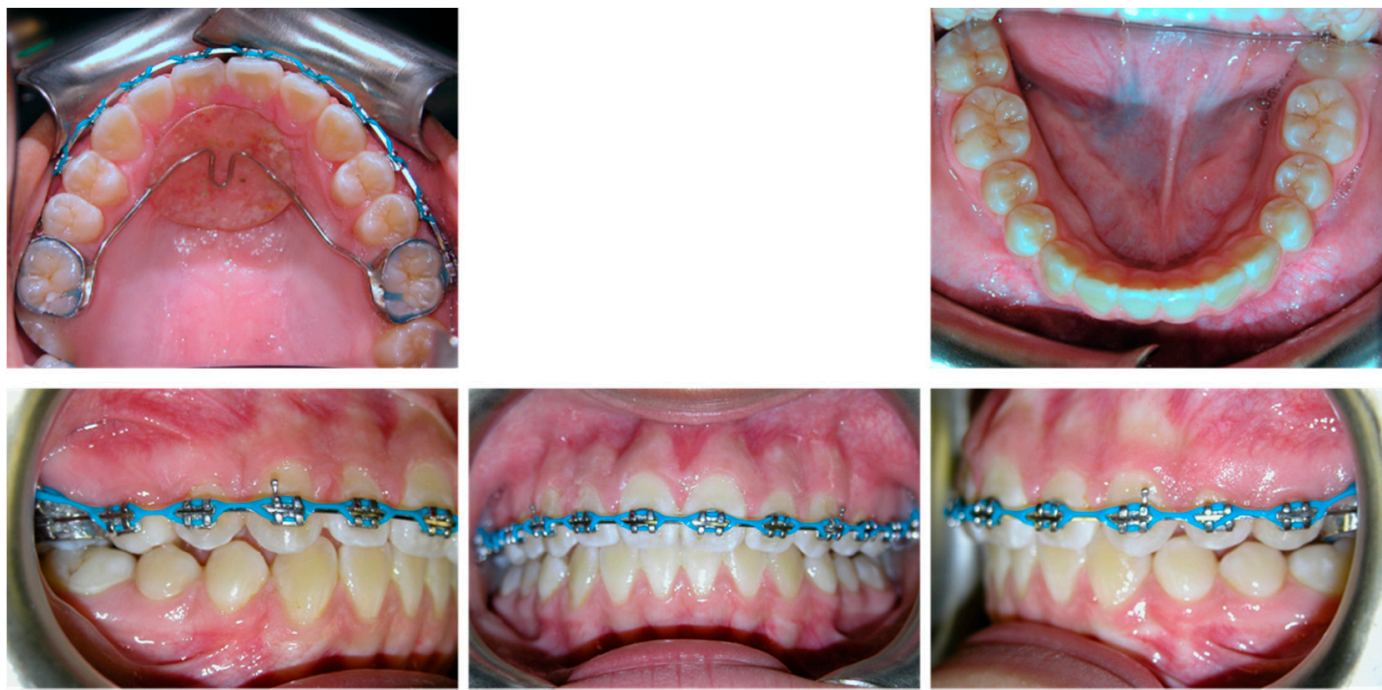

Figure 4. The intraoral progress photos of case 1 demonstrate maxillary arch space closure.
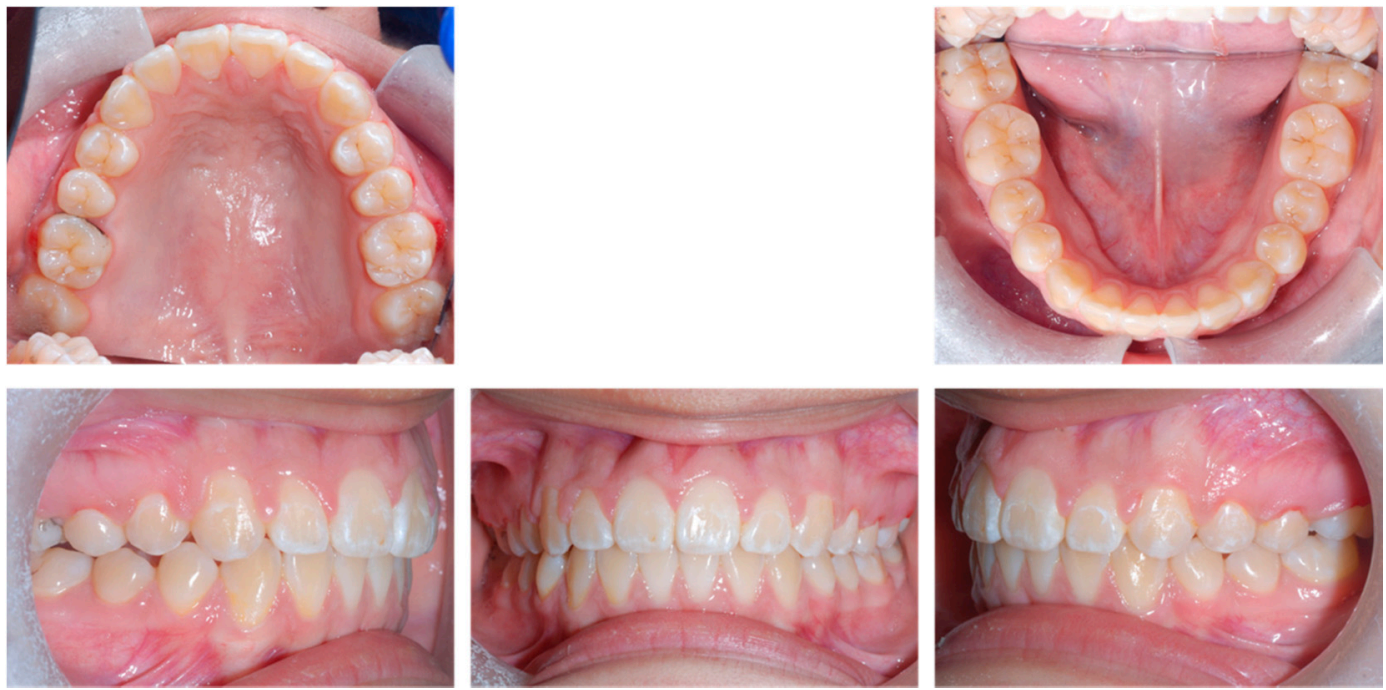

Figure 5. The final intraoral photos of case 1.

The treatment objectives were to (1) distalize the maxillary right quadrant and canine to a Class I relationship; (2) maintain the Class I canine and molar relationship on the left side; (3) correct the maxillary midline and anterior crossbite to achieve ideal overbite and overjet; and (4) correct the mandibular mild crowding.

Based on the treatment objectives, the treatment plan was designed as follows: (1) unilateral right maxillary molar distalization with the modified Nance appliance technique, then distalizing the maxillary premolars and canines to achieve Class I canine and molar relationships on the right side without using the Class II elastics; (2) slightly procline the uprighted maxillary incisors, correct the anterior crossbite and coordinate the midline; (3) level and align the mandibular arch, slight interproximal reduction to help correct the crowding. The treatment plan was well-accepted by the patient and parents. 

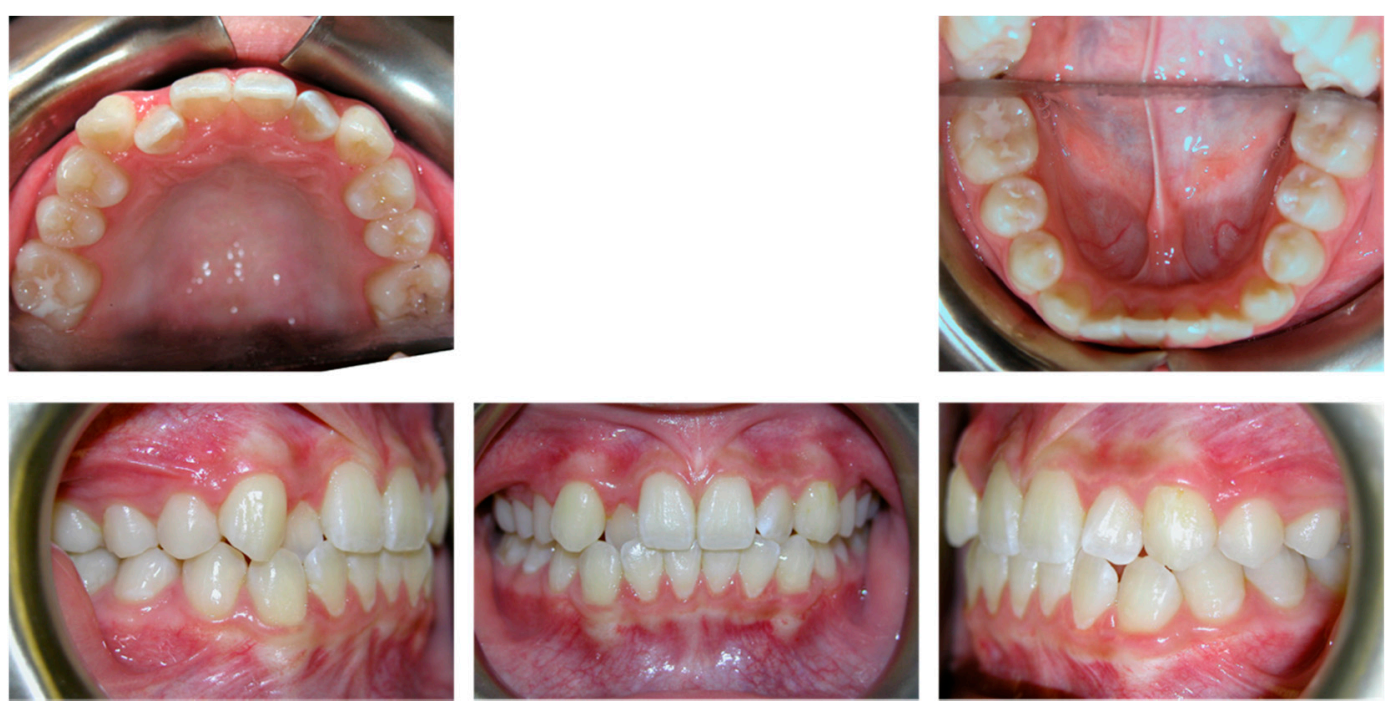

Figure 6. The initial intraoral photos of case 2.

The modified Nance appliance was delivered with mash pads cemented to four maxillary premolars as anchorage. The distalization of molars was performed with the right side of the maxillary arch (Figure 7, top) until a super Class I molar relationship was achieved (Figure 7). The subsequent treatment sequence was the same as described above. At the end of the treatment, satisfactory dental alignment, bilateral Class I canine and molar relationships, and ideal overjet and overbite were achieved (Figure 8). In addition, dental midlines were coincident with the facial midline, and protrusive and canine guidance was obtained.
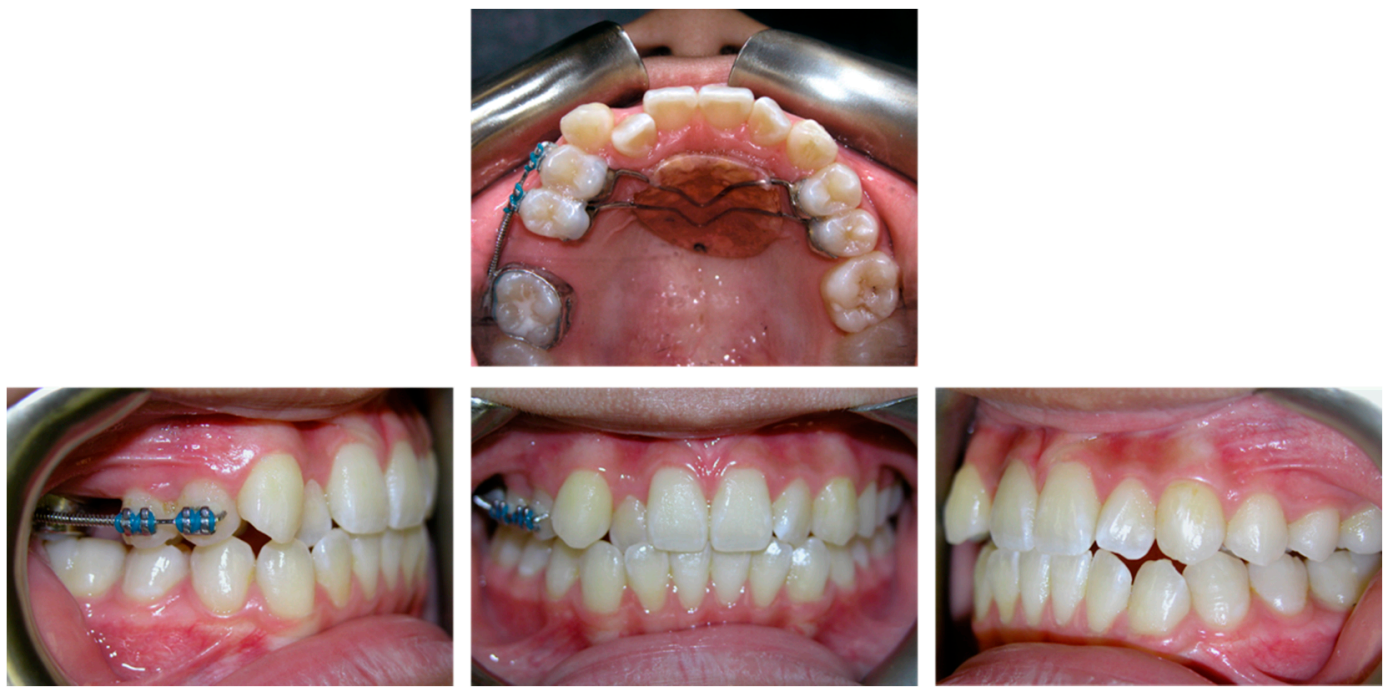

Figure 7. The intraoral progress photos of case 2 demonstrate the super Class I molar relationship achieved on the right side with the modified Nance appliance as anchorage. 

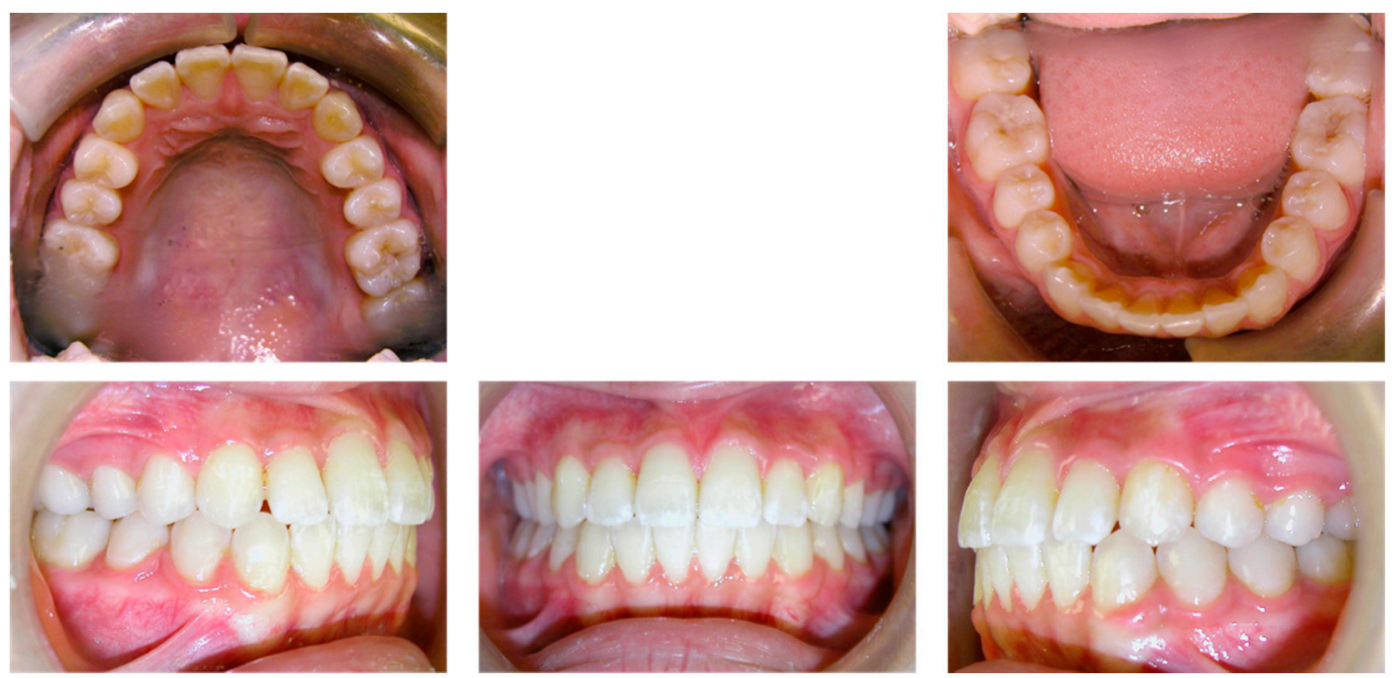

Figure 8. The final intraoral photos of case 2.

\section{Discussion}

Here we showed two cases that had achieved sufficient maxillary molar distalization by utilizing the modified Nance appliance as anchorage. It is worth noting that both cases had maxillary second molars erupted into the arch before starting the distalization. Based on the clinical observation of the authors, the eruption stages of the maxillary second molars do not significantly affect the treatment efficiency of the modified Nance appliance technique. This observation is similar to the clinical results of other intra-arch maxillary molar distalizers $[16,32,33]$. There is even less distal tipping of the first molars after molar distalization when the second molars are already fully erupted [34]. In the scenario that maxillary second molars have erupted, it is unnecessary to distalize the second molars first, then to distalize the first molar. In other words, the maxillary molars can be distalized at the same time by the modified Nance appliance technique. However, a larger force should be applied when the second molars are erupted than when the second molars are not erupted [35].

On the other hand, whether the presence of a third molar follicle had a significant effect on molar distalization is controversial $[32,36,37]$. Furthermore, whether the total maxillary arch distalization affected the eruption of the third molars is also not conclusive [38,39]. We suggest that if the position of the third molars is acceptably evaluated by the oral surgeons, germectomy or extraction of maxillary third molars right before molar distalization should be considered to utilize the effects from regional acceleratory phenomenon [40].

The key factor of the modified Nance appliance is the big acrylic button, as a bigger contacting area of the palate could withstand more force under the same pressure (Force $=$ Pressure $\times$ Square), which means more anchorage support from the anterior palate. Since the force and counterforce are in the anterior-posterior direction during molar distalization, the depth of the palatal vault needs to be evaluated while designing the modified Nance appliance. If the patient has a shallow palate, the rugae area would be too flat to withstand the sagittal force exerted from the open coil between the second premolar and molar (Table 1). In that case, an anterior palatal TAD is suggested to be cemented with the modified Nance appliance as additional anchorage support. However, the TAD position should be planned carefully to avoid incisive canal and anterior tooth root perforation [41]. In addition, the modified Nance appliance is bonded to the premolars, which is separate from the molars. A previous study found that when distalizing the molars with the distal jet appliance, its forces tended to cause some inferior rotation of the Nance palatal button [19], thereby not only causing premolar tipping, but also increasing the risk of anchorage loss as the tight contact between the acrylic button and the palatal tissue has been lost. Thus, by separating the Nance acrylic button with maxillary molars during molar 
distalization, the modified Nance appliance has a higher potential to hold the anchorage unit in place compared to other one-piece molar distalizers.

Table 1. The clinical indications of the modified Nance appliance usage.

\begin{tabular}{|c|c|}
\hline Indications & Use with Caution \\
\hline $\begin{array}{l}\text { Bilateral or unilateral maxillary } \\
\text { molar distalization }\end{array}$ & - \\
\hline $\begin{array}{l}\text { Patients could not afford mandibular } \\
\text { anterior teeth proclination }\end{array}$ & - \\
\hline Amount of distalization within $4 \mathrm{~mm}$ & $\begin{array}{l}\text { Amount of distalization larger than } 4 \mathrm{~mm} \text { (need to } \\
\text { consider extraction of maxillary third molars and/or } \\
\text { support from palatal TADs) }\end{array}$ \\
\hline Child/Adolescent & Adult \\
\hline $\begin{array}{l}\text { Brachyfacial or mesofacial skeletal } \\
\text { patterns }\end{array}$ & $\begin{array}{l}\text { Dolichofacial skeletal pattern (need to incorporate } \\
\text { molar intrusion mechanics) }\end{array}$ \\
\hline Regular or deep palatal vault & $\begin{array}{c}\text { Shallow palatal vault (need support from anterior } \\
\text { palatal TADs) }\end{array}$ \\
\hline
\end{tabular}

Another unique factor that needs to be mentioned is the initial premolar brackets position that allows the insertion of the 0.018-inch SS archwire right away without the need for the leveling and aligning stage. Previous studies suggested that molar distalization should be accomplished before bonding the maxillary brackets $[19,42,43]$, as "there is little anchorage value to mobilized teeth" [44]. However, it is worth noting that the key is if there is active periodontal remodeling around the anchorage teeth, not if there are any brackets on these teeth. Thus, the premolar brackets should be bonded based on the passive draw line of the archwire in relation to the first molar bands instead of the ideal bracket's position. By bonding the brackets, it makes it possible to place the distalization activating unit on the buccal side of the dental arch. It not only improves the patients' comfort and reduces chairside time, which are the benefits of buccal appliances compared to the lingual appliances [22-26], but also allows the distalization force to be applied on the buccal side of the molars, which allows both distalization and distopalatal rotation. This mode of rotation is favorable in the management of Class II molar relationships as most patients with Class II have their maxillary first molars rotated mesially around their lingual roots [16,21,45].

In addition, the current technique has potential benefits on the periodontal status of the patients. First of all, by limiting the molar distalization activation within the maxillary arch only, the current technique avoids the proclination of the mandibular incisors compared to other inter-arch mechanics, which may cause labial alveolar bone loss and gingival recession at the mandibular incisor region [14]. Secondly, by utilizing the NiTi or SS open coil spring to distalize the molars, our technique allows for maintaining light and constant forces, which could reduce the risk of root resorption and periodontal trauma [46]. Thirdly, as the 0.018-inch SS archwire used in this system could be easily adjusted and reinserted during the distalization period, a gable bend between the second premolar and first molar can be added to the archwire to correct molar root angulation when needed. This modification could help reduce the chance of root proximity in the mesial and distal of the maxillary first molars and reduce the risk of periodontal disease [47]. Nevertheless, it cannot be ignored that for all maxillary molar distalization mechanics, the maxillary second molar is moved in the maxillary tuberosity, where there is abundant attached gingiva. Although not observed in the two cases presented here, there are some reports that such distalization movement could cause a deep pseudo pocket around the maxillary second molars, particularly on the distal surface of the teeth, which need periodontal management $[48,49]$. However, to the authors' best knowledge, no studies have been conducted to evaluate the periodontal effects resulting from any available molar distalizers. Thus, further research on this topic is needed. 


\section{Conclusions}

In summary, we shared a simple and effective intra-arch maxillary molar distalization technique. The appliances used in this technique are easy to be fabricated, delivered, and activated. In addition, either bilateral or unilateral maxillary molar distalization could be achieved utilizing this technique without affecting mandibular dentition.

Author Contributions: Conceptualization, C.-H.C.; methodology, C.-H.C.; investigation, C.-H.C.; resources, C.-H.C.; writing-original draft preparation, C.L.; writing-review and editing, C.-H.C.; supervision, C.-H.C.; project administration, C.-H.C. All authors have read and agreed to the published version of the manuscript.

Funding: This research received no external funding.

Institutional Review Board Statement: Not applicable.

Informed Consent Statement: Patient consent was waived as all the treatments followed the standard care, and no personal identification information was included in this paper.

Data Availability Statement: Not applicable.

Conflicts of Interest: The authors declare no conflict of interest.

\section{References}

1. Sabri, R. Treatment of a severe arch-length deficiency with anteroposterior and transverse expansion: Long-term stability. Am. J. Orthod. Dentofac. Orthop. 2010, 137, 401-411. [CrossRef]

2. Alogaibi, Y.A.; Al-Fraidi, A.A.; Alhajrasi, M.K.; Alkhathami, S.S.; Hatrom, A.; Afify, A.R. Distalization in Orthodontics: A Review and Case Series. Case Rep. Dent. 2021, 2021, 8843959. [CrossRef]

3. Antonarakis, G.S.; Kiliaridis, S. Maxillary molar distalization with noncompliance intramaxillary appliances in Class II malocclusion. A systematic review. Angle Orthod. 2008, 78, 1133-1140. [CrossRef] [PubMed]

4. Noorollahian, S.; Alavi, S.; Shirban, F. Non-compliance Appliances for Upper Molar Distalization: An Overview. Int. J. Orthod. Milwaukee. 2015, 26, 31-36. [PubMed]

5. Berkman, M.E.; Haerian, A.; McNamara, J.A., Jr. Interarch maxillary molar distalization appliances for Class II correction. J. Clin. Orthod. 2008, 42, 35-42. [PubMed]

6. Janson, G.; Sathler, R.; Fernandes, T.M.; Branco, N.C.; Freitas, M.R. Correction of Class II malocclusion with Class II elastics: A systematic review. Am. J. Orthod. Dentofac. Orthop. 2013, 143, 383-392. [CrossRef] [PubMed]

7. Kim-Berman, H.; McNamara, J.A., Jr.; Lints, J.P.; McMullen, C.; Franchi, L. Treatment effects of the Carriere((R)) Motion 3D appliance for the correction of Class II malocclusion in adolescents. Angle Orthod. 2019, 89, 839-846. [CrossRef] [PubMed]

8. Aslan, B.I.; Akarslan, Z.Z.; Karadag, O. Effects of Angle class II correction with the Forsus fatigue resistant device on mandibular third molars: A retrospective study. J. Orofac. Orthop. 2021, 82, 403-412. [CrossRef] [PubMed]

9. Ardeshna, A.; Bogdan, F.; Jiang, S. Class II correction in orthodontic patients utilizing the Mandibular Anterior Repositioning Appliance (MARA). Angle Orthod. 2019, 89, 404-410. [CrossRef] [PubMed]

10. Taylor, K.L.; Evangelista, K.; Muniz, L.; Ruellas, A.C.O.; Valladares-Neto, J.; McNamara, J., Jr.; Franchi, L.; Kim-Berman, H.; Cevidanes, L.H.S. Three-dimensional comparison of the skeletal and dentoalveolar effects of the Herbst and Pendulum appliances followed by fixed appliances: A CBCT study. Orthod. Craniofac. Res. 2020, 23, 72-81. [CrossRef] [PubMed]

11. George, S.M.; Campbell, P.M.; Tadlock, L.P.; Schneiderman, E.; Buschang, P.H. Keys to Class II correction: A comparison of 2 extraction protocols. Am. J. Orthod. Dentofac. Orthop. 2021, 159, 333-342. [CrossRef] [PubMed]

12. Quinzi, V.; Marchetti, E.; Guerriero, L.; Bosco, F.; Marzo, G.; Mummolo, S. Dentoskeletal Class II Malocclusion: Maxillary Molar Distalization with No-Compliance Fixed Orthodontic Equipment. Dent. J. 2020, 8, 26. [CrossRef]

13. Bowman, A.C.; Saltaji, H.; Flores-Mir, C.; Preston, B.; Tabbaa, S. Patient experiences with the Forsus Fatigue Resistant Device. Angle Orthod. 2013, 83, 437-446. [CrossRef] [PubMed]

14. Matsumoto, K.; Sherrill-Mix, S.; Boucher, N.; Tanna, N. A cone-beam computed tomographic evaluation of alveolar bone dimensional changes and the periodontal limits of mandibular incisor advancement in skeletal Class II patients. Angle Orthod. 2020, 90, 330-338. [CrossRef] [PubMed]

15. Li, C.; Sfogliano, L.; Jiang, W.; Lee, H.; Zheng, Z.; Chung, C.H.; Jones, J. Total maxillary arch distalization by using headgear in an adult patient. Angle Orthod. 2021, 91, 267-278. [CrossRef] [PubMed]

16. Ghosh, J.; Nanda, R.S. Evaluation of an intraoral maxillary molar distalization technique. Am. J. Orthod. Dentofac. Orthop. 1996, 110, 639-646. [CrossRef]

17. Jones, R.D.; White, J.M. Rapid Class II molar correction with an open-coil jig. J. Clin. Orthod. 1992, 26, 661-664.

18. Papadopoulos, M.A.; Melkos, A.B.; Athanasiou, A.E. Noncompliance maxillary molar distalization with the first class appliance: A randomized controlled trial. Am. J. Orthod. Dentofac. Orthop. 2010, 137, 586.e1-586.e13; discussion 586-587. [CrossRef] 
19. Bolla, E.; Muratore, F.; Carano, A.; Bowman, S.J. Evaluation of maxillary molar distalization with the distal jet: A comparison with other contemporary methods. Angle Orthod. 2002, 72, 481-494. [CrossRef]

20. Kook, Y.A.; Bayome, M.; Park, J.H.; Kim, K.B.; Kim, S.H.; Chung, K.R. New approach of maxillary protraction using modified C-palatal plates in Class III patients. Korean J. Orthod. 2015, 45, 209-214. [CrossRef]

21. Abdelhady, N.A.; Tawfik, M.A.; Hammad, S.M. Maxillary molar distalization in treatment of angle class II malocclusion growing patients: Uncontrolled clinical trial. Int. Orthod. 2020, 18, 96-104. [CrossRef]

22. Rai, A.K.; Rozario, J.E.; Ganeshkar, S.V. Comparison of speech performance in labial and lingual orthodontic patients: A prospective study. Dent. Res. J. 2014, 11, 663-675.

23. Favale, M.L.; Fusco, R.; Lesti, M.; Horodynski, M.; Toni, B. Lingual vs. Labial Fixed Orthodontic Appliances: Comparison of Adverse effects. WebmedCentral Orthod. 2017, 8, WMC005367.

24. Papageorgiou, S.N.; Golz, L.; Jager, A.; Eliades, T.; Bourauel, C. Lingual vs. labial fixed orthodontic appliances: Systematic review and meta-analysis of treatment effects. Eur. J. Oral. Sci. 2016, 124, 105-118. [CrossRef]

25. Khattab, T.Z.; Farah, H.; Al-Sabbagh, R.; Hajeer, M.Y.; Haj-Hamed, Y. Speech performance and oral impairments with lingual and labial orthodontic appliances in the first stage of fixed treatment. Angle Orthod. 2013, 83, 519-526. [CrossRef] [PubMed]

26. Kumar, S.; Sonal, S.; Khanum, A.; Rahman, S.N.; Bano, N. Comparative Biomechanics of Labial versus Lingual Fixed Appliances-A Review. J. Dent. Orofac. Res. 2017, 13, 56-60.

27. Chou, A.H.K.; Park, J.H.; Shoaib, A.M.; Lee, N.K.; Lim, H.J.; Abdulwhab, A.A.; Alfawaz, F.; Kook, Y.A. Total maxillary arch distalization with modified C-palatal plates in adolescents: A long-term study using cone-beam computed tomography. Am. J. Orthod. Dentofac. Orthop. 2021, 159, 470-479. [CrossRef] [PubMed]

28. Miyazawa, K.; Shibata, M.; Tabuchi, M.; Kawaguchi, M.; Shimura, N.; Goto, S. Optimal sites for orthodontic anchor screw placement using panoramic images: Risk of maxillary sinus perforation and contact with adjacent tooth roots during screw placement. Prog. Orthod. 2021, 22, 46. [CrossRef]

29. Motoyoshi, M.; Sanuki-Suzuki, R.; Uchida, Y.; Saiki, A.; Shimizu, N. Maxillary sinus perforation by orthodontic anchor screws. J. Oral. Sci. 2015, 57, 95-100. [CrossRef] [PubMed]

30. Giudice, A.L.; Rustico, L.; Longo, M.; Oteri, G.; Papadopoulos, M.A.; Nucera, R. Complications reported with the use of orthodontic miniscrews: A systematic review. Korean J. Orthod. 2021, 51, 199-216. [CrossRef]

31. Chugh, T.; Jain, A.K.; Jaiswal, R.K.; Mehrotra, P.; Mehrotra, R. Bone density and its importance in orthodontics. J. Oral. Biol. Craniofac. Res. 2013, 3, 92-97. [CrossRef] [PubMed]

32. Flores-Mir, C.; McGrath, L.; Heo, G.; Major, P.W. Efficiency of molar distalization associated with second and third molar eruption stage. Angle Orthod. 2013, 83, 735-742. [CrossRef] [PubMed]

33. Nienkemper, M.; Wilmes, B.; Pauls, A.; Yamaguchi, S.; Ludwig, B.; Drescher, D. Treatment efficiency of mini-implant-borne distalization depending on age and second-molar eruption. J. Orofac. Orthop. 2014, 75, 118-132. [CrossRef]

34. Kinzinger, G.S.M.; Hourfar, J.; Lisson, J.A. Efficiency of the skeletonized Pendulum K appliance for non-compliance maxillary molar distalization: A clinical pilot study. J. Orofac. Orthop. 2021, 82, 391-402. [CrossRef] [PubMed]

35. Serafin, M.; Fastuca, R.; Castellani, E.; Caprioglio, A. Occlusal Plane Changes After Molar Distalization With a Pendulum Appliance in Growing Patients with Class II Malocclusion: A Retrospective Cephalometric Study. Turk. J. Orthod. 2021, $34,10-17$. [CrossRef] [PubMed]

36. Kang, J.M.; Park, J.H.; Bayome, M.; Oh, M.; Park, C.O.; Kook, Y.A.; Mo, S.S. A three-dimensional finite element analysis of molar distalization with a palatal plate, pendulum, and headgear according to molar eruption stage. Korean J. Orthod. 2016, 46, 290-300. [CrossRef] [PubMed]

37. Kinzinger, G.S.; Fritz, U.B.; Sander, F.G.; Diedrich, P.R. Efficiency of a pendulum appliance for molar distalization related to second and third molar eruption stage. Am. J. Orthod. Dentofac. Orthop. 2004, 125, 8-23. [CrossRef] [PubMed]

38. Kang, H.; Lee, N.K.; Kim, J.; Park, J.H.; Kim, Y.; Kook, Y.A. Factors associated with the maxillary third molar position after total arch distalization using a modified C-palatal plate in adolescents. Orthod. Craniofac. Res. 2021, 24, 31-38. [CrossRef]

39. Lee, Y.J.; Kook, Y.A.; Park, J.H.; Park, J.; Bayome, M.; Vaid, N.R.; Kim, Y. Short-term cone-beam computed tomography evaluation of maxillary third molar changes after total arch distalization in adolescents. Am. J. Orthod. Dentofac. Orthop. 2019, 155, 191-197. [CrossRef]

40. Verna, C. Regional Acceleratory Phenomenon. Front. Oral. Biol. 2016, 18, 28-35. [CrossRef] [PubMed]

41. Eigenwillig, P.; Ludwig, B.; Bumann, A. Safe and Precise TAD Placement in the Anterior Palate with Simple and Inexpensive TAD Guides. In Temporary Anchorage Devices in Clinical Orthodontics; John Wiley \& Sons, Inc.: Hoboken, NJ, USA, 2020 ; pp. 577-586.

42. Bowman, S.J. Modifications of the distal jet. J. Clin. Orthod. 1998, 32, 549-556. [PubMed]

43. Bowman, S.J. Upper-Molar Distalization and the Distal Jet. J. Clin. Orthod. 2016, 50, 159-169. [PubMed]

44. Melsen, B.; Bosch, C. Different approaches to anchorage: A survey and an evaluation. Angle Orthod. 1997, 67, 23-30. [CrossRef] [PubMed]

45. Gelgor, I.E.; Karaman, A.I.; Buyukyilmaz, T. Comparison of 2 distalization systems supported by intraosseous screws. Am. J. Orthod. Dentofac. Orthop. 2007, 131, 161.e1-161.e8. [CrossRef]

46. Caprioglio, A.; Beretta, M.; Lanteri, C. Maxillary molar distalization: Pendulum and Fast-Back, comparison between two approaches for Class II malocclusion. Prog. Orthod. 2011, 12, 8-16. [CrossRef] [PubMed] 
47. Vermylen, K.; De Quincey, G.N.; Wolffe, G.N.; van't Hof, M.A.; Renggli, H.H. Root proximity as a risk marker for periodontal disease: A case-control study. J. Clin. Periodontol. 2005, 32, 260-265. [CrossRef] [PubMed]

48. Choi, Y.J.; Lee, J.S.; Cha, J.Y.; Park, Y.C. Total distalization of the maxillary arch in a patient with skeletal Class II malocclusion. Am. J. Orthod. Dentofac. Orthop. 2011, 139, 823-833. [CrossRef]

49. Tan, J.M.; Liu, Y.-M.; Chiu, H.-C.; Chen, Y.-J. Molar Distalization by Temporary Anchorage Devices (TAD s)—A Review Article. Taiwan. J. Orthod. 2017, 29, 2. [CrossRef] 